\title{
Photoactive hexanuclear molybdenum nanoclusters embedded in molecular organogels
}

Carla Arnau del Valle, ${ }^{a}$ Carles Felip-León, ${ }^{a}$ César A. Angulo-Pachón, ${ }^{a}$ Maxim Mikhailov, ${ }^{b}$ Maxim N. Sokolov, ${ }^{b}$ Juan F. Miravet*a and Francisco Galindo*a

[a] Universitat Jaume I, Departamento de Química Inorgánica y Orgánica, Avda. Sos Baynat s/n, 12071, Castellón, Spain.

[b] Nikolaev Institute of Inorganic Chemistry, Siberian Branch of the Russian Academy of

Sciences, 3 Acad. Lavrentiev Prosp., 630090 Novosibirsk, Russia. 


\begin{abstract}
Hexanuclear molybdenum clusters are attractive species due to their outstanding photonic properties, and in the past they have been attached to a variety of supports such as organic polymers and inorganic nanoparticles, as described in the recent literature. Here, a cluster of formula $\mathrm{TBA}_{2}\left[\mathrm{Mo}_{6} \mathrm{I}_{8} \mathrm{Ac}_{6}\right](\mathrm{TBA}=$ tetrabutylammonium, $\mathrm{Ac}=$ acetate $)$ has been supported on molecular organogels for the first time, resulting in a new soft materials with remarkable photoactivity. Electron and confocal microscopic analyses showed the alignment of the nanoclusters to 1D selfassembled fibres formed by the organic gelator, and emission spectroscopy corroborated the interaction of the emissive clusters with such fibrillary structures. The new hybrid system is a deep-red emissive material (phosphorescence maximum at ca. $680 \mathrm{~nm}$ ), with chromatic coordinates $\mathrm{x}=0.725, \mathrm{y}=0.274$, capable of generating efficiently singlet oxygen $\left({ }^{1} \mathrm{O}_{2}\right)$ upon illumination with white light, as demonstrated by the photo-oxygenation of 9,10dimethylanthracene and 1,5-dihydroxynaphthalene. The organogels can been made in dichloromethane and toluene, and in both solvents display phosphorescence emission and photocatalytic properties.
\end{abstract}


Hexanuclear molybdenum anionic cluster units with formula $\left[\operatorname{Mo}_{6} \mathrm{~L}_{8}{ }_{8} \mathrm{~L}_{6}{ }^{\mathrm{a}}{ }^{2-}\left(\mathrm{L}^{\mathrm{i}}\right.\right.$ and $\mathrm{L}^{\mathrm{a}}$ are inner and apical ligands respectively) have attracted much attention due to their notable emissive properties (in particular, the iodides, $\mathrm{L}^{\mathrm{i}}=\mathrm{I}$ ). The synthesis and characterization of a vast collection of such complexes has been described. ${ }^{1-15}$ They display phosphorescence in the red and near infrared regions (580-900 nm), when excited with blue light. Apart from the emissive properties, these clusters have a notable capacity to generate singlet oxygen $\left({ }^{1} \mathrm{O}_{2}\right)$ upon illumination. Hence, the research on these systems has boosted in recent years, providing the numerous applications of ${ }^{1} \mathrm{O}_{2}$ in photocatalysis ${ }^{16}$ and photodynamic therapy (PDT). ${ }^{17}$

A number of metallic clusters have been encapsulated in solid supports, leading to photoactive materials. For instance, they have been entrapped in poly (4-vinylpyridine), ${ }^{2,18}$ poly (1-trimethylsilyl-1-propyne), ${ }^{19}$ polyurethane, ${ }^{12,20}$ silicone, ${ }^{21,22}$ amorphous carbon, ${ }^{23}$ polymethylmethacrylate, ${ }^{24-27}$ poly(D,L-lactide-co-glycolide) ${ }^{28}$ polymeric hydrogel nanoparticles ${ }^{29}$ polystyrene, ${ }^{30-35} \mathrm{SiO}_{2}{ }^{8,36-40}$ and $\mathrm{ZnO}^{8,41}$ Some of these materials have proved useful for technological applications such as solid state emission, ${ }^{8,25,41}$ oxygen sensing, ${ }^{19,20}$ time-gated bioimaging, ${ }^{39}$ photochemical oxygenations ${ }^{2,31,33,34,37}$ and photodynamic therapy (both anticancer $^{28,38,40,42}$ and antibacterial $\left.{ }^{31,34}\right)$.

Despite the large number of materials mentioned above, no usage of a molecular organogel as support for any $\left[\mathrm{Mo}_{6} \mathrm{~L}_{8}{ }_{8} \mathrm{~L}_{6}{ }_{6}\right]^{2-}$ cluster has been reported. Organogels are soft materials formed by low-molecular weight species forming a self-assembled fibrillary network (SAFiN) able to immobilize bulk solvent, yielding a solid-like appearance. ${ }^{43-45}$ Here we describe a new hybrid material comprised by a hexanuclear molybdenum cluster immobilized on an organogel. The new material displays deep-red emission and is able to act as a photocatalyst for oxygenation reactions. In this study we have selected $\mathrm{TBA}_{2}\left[\mathrm{Mo}_{6} \mathrm{I}_{8} \mathrm{Ac}_{6}\right]$ (1 in Figure 1 ; Ac is acetate and TBA is 
tetrabutylammonium) as a photoactive cluster with well-proven photoactivity. ${ }^{31,34}$ Molecule 2 (Figure 1) was selected as organogelator because it forms efficiently transparent gels in dichloromethane and toluene.
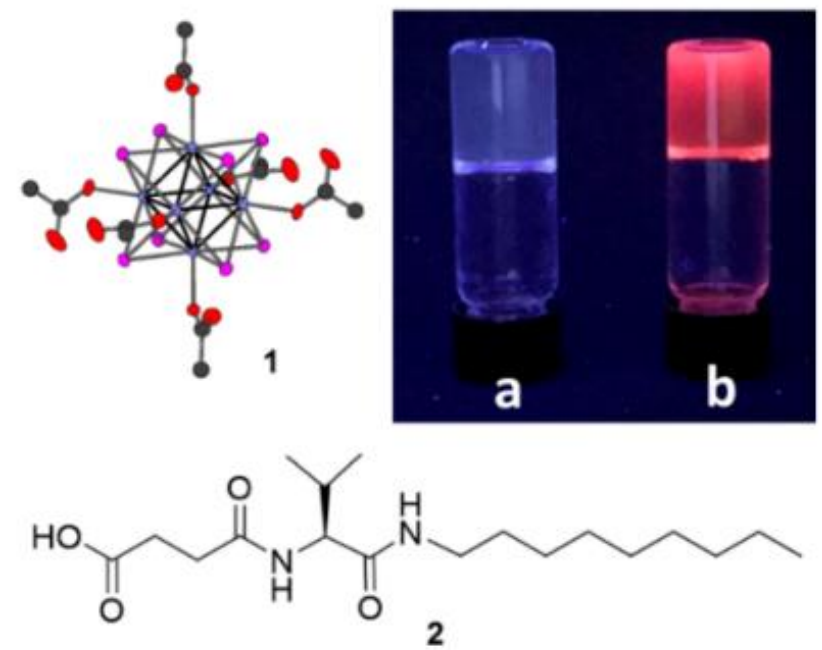

Figure 1. Structures of cluster 1 and molecular organogelator 2. Picture showing a gel made with 2, under UV light (a: undoped gel; b: doped with 1). For both gels [2] $=14.6 \mathrm{mM}(5 \mathrm{mg} / \mathrm{mL})$ and for $b[1]=0.25 \mathrm{mM}(0.5 \mathrm{mg} / \mathrm{mL})$.

Gels were prepared by dissolving $\mathbf{1}$ and $\mathbf{2}$ at the appropriate concentrations in hot solvent (dichloromethane or toluene) and allowing to cool down to room temperature. After a few minutes, the formation of the gels is evident from the fact that the solvent does not flow after inversion of the recipient (see picture in Figure 1). The gels thus formed are translucent, and upon illumination with UV light of $365 \mathrm{~nm}$ display a reddish emission, corresponding to the phosphorescence of $\mathbf{1}$. Similar red emission has been reported for hexanuclear molybdenum clusters embedded in polymeric matrices. ${ }^{20,25}$ In the present work we focus on dichloromethane as solvent since gels in this solvent are easier to prepare (lower heating temperature than toluene). Other solvents are currently under study. 
The stability of the gels was tested by means of UV-vis absorption measurements at $800 \mathrm{~nm}$. At this wavelength, the transmitted light is scattered in the gel samples (at room temperature), but not when the system is completely fluid (higher temperatures). Using this property, in previous works we were able to determine gelation temperatures $\left(\mathrm{T}_{\mathrm{g}}\right)$ of gels doped with guest dyes ${ }^{46}$ and nanoparticles. ${ }^{47,48}$ In the case now described a series of variable-temperature absorption measurements afforded a $\mathrm{T}_{\mathrm{g}}$ of $32.1^{\circ} \mathrm{C}$, for undoped gel of 2, and a $\mathrm{T}_{\mathrm{g}}$ of $30.3{ }^{\circ} \mathrm{C}$ for the hybrid comprised by $\mathbf{1}+\mathbf{2}$ (Figure $\mathrm{S} 1$, Supporting Information). This small difference indicates that the stability of the gel is not influenced by the presence of the dopant cluster.

Transmission Electron Microscopy (TEM) analysis of the gels revealed a fibrous structure of self-assembled 2, similar to analogous materials described so far. Noticeably, the fibres of $\mathbf{1}$ presented black dots (see Figures 2a,b) corresponding to the incorporated molybdenum clusters (aggregates). Similar associations have been found in hybrid materials formed by SAFINs and CdSe/ZnS quantum dots. ${ }^{47,48}$ The samples were also examined by means of scanning transmission electron microscopy (STEM), and in this case, a higher contrast was found between the supramolecular structures (in grey colour in Figure 2c,d) and the metal cluster aggregates (white dots). The chemical identity of the white spots was confirmed by means of Energy Dispersive Xray Spectroscopy (EDS) since it showed unequivocally the presence of molybdenum and iodine atoms in the white structures but not in the grey ones. The alignment of the molybdenum clusters in 1D supramolecular scaffolds such as those depicted in Figure 2 has not been reported to date (additional pictures can be seen in the Supporting Information: Figures S4 - S7). 

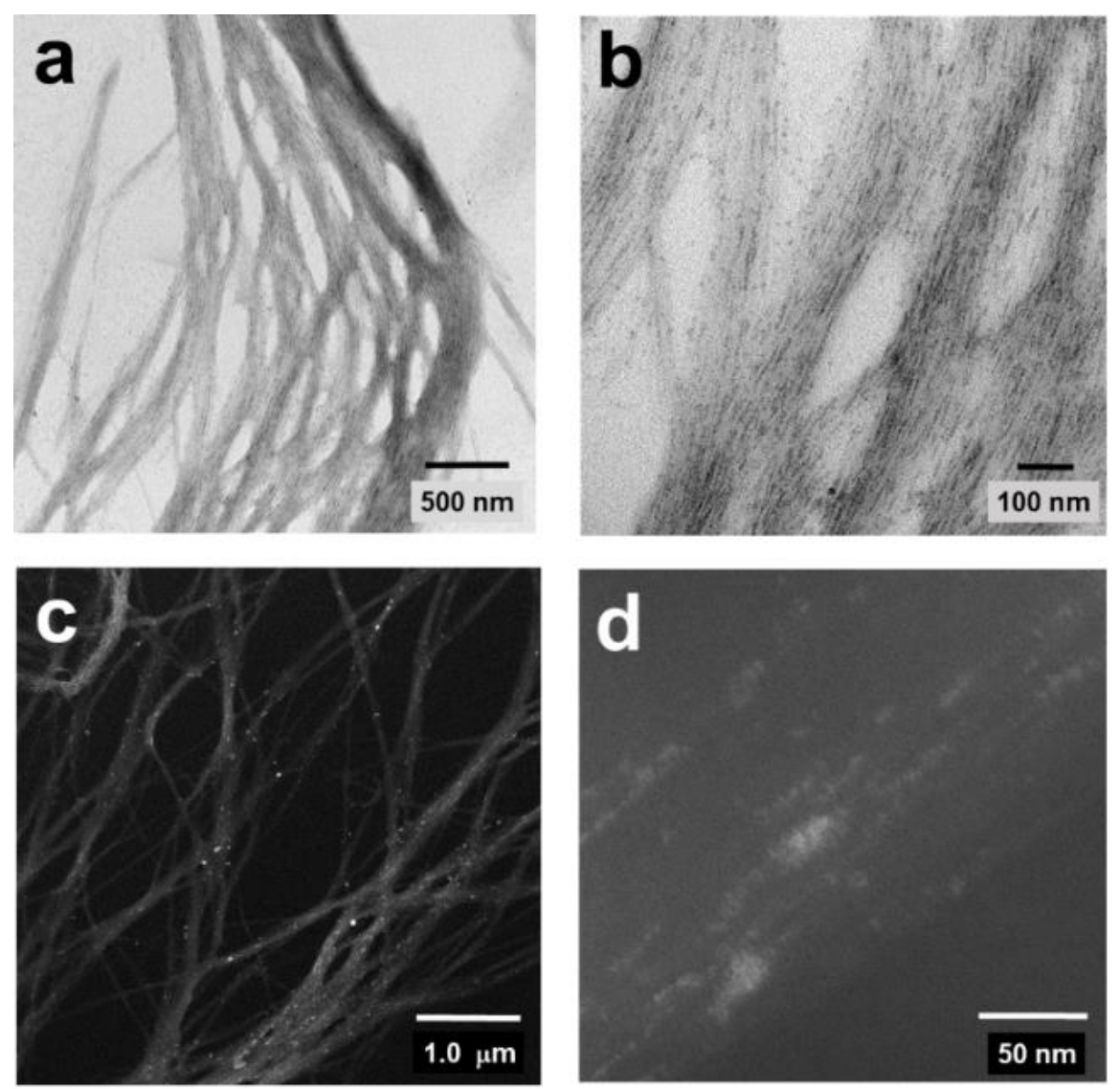

Figure 2. TEM pictures of molecular gels of $\mathbf{2}$ embedding nanoclusters of $\mathbf{1}$. a,b show TEM images of the gels and c,d show STEM images. Conditions: [2] $=14.6 \mathrm{mM}(5 \mathrm{mg} / \mathrm{mL}),[1]=0.25 \mathrm{mM}$ $(0.5 \mathrm{mg} / \mathrm{mL})$.

The new hybrid materials were also studied by means of confocal laser scanning microscopy (CLSM). This technique has been used by us in the past to study the process of energy transfer in orthogonally assembled fibrillary networks. ${ }^{49}$ In the present case, the dichloromethane gel was examined under the microscope, and a series of long red emitting fibres (several microns length) were observed, when excitation was set to $488 \mathrm{~nm}$ (see Figure 3). In order to confirm that this emission was the phosphorescence of the cluster 1 and not an instrumental artifact, the emission spectrum of the fibres was recorded with the confocal microscope. As it can be seen in Figure 4, the maximum of the emission from the 
red fibrillary structures is at ca. $670 \mathrm{~nm}$. This value matches the emission maxima of the cluster embedded in the gel measured by steady state fluorometry (in a cuvette) peaking at $672 \mathrm{~nm}$ (Figure 4).
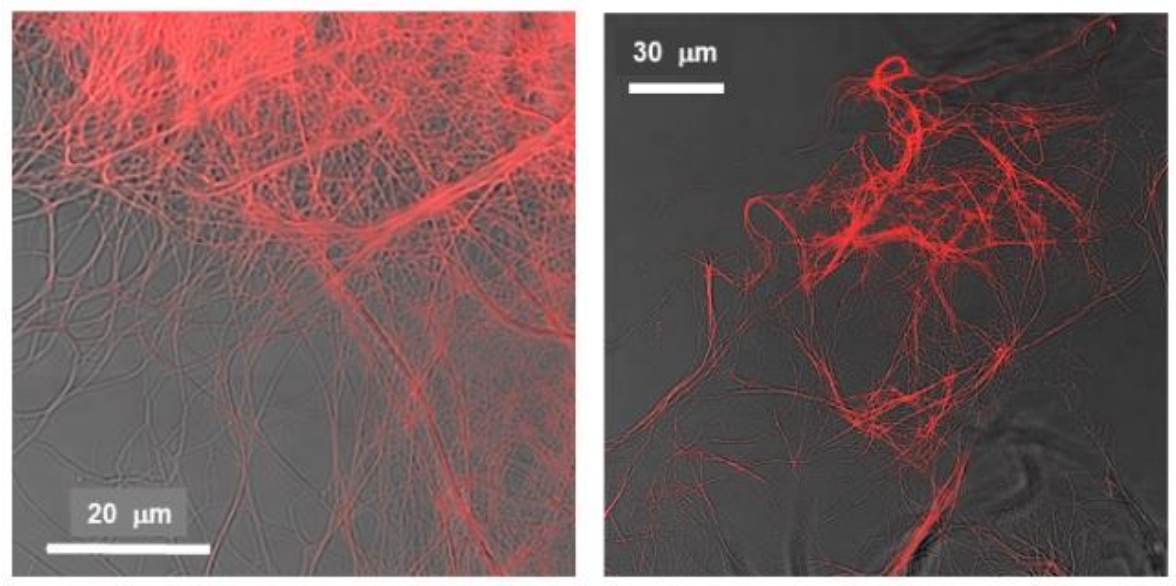

Figure 3. CLSM images showing the fibrillary network of $\mathbf{2}$ stained with molybdenum cluster $\mathbf{1}$. $\lambda_{\mathrm{ex}}=488 \mathrm{~nm}, \Delta \lambda=590-730 \mathrm{~nm}$. Conditions: $[2]=14.6 \mathrm{mM}(5 \mathrm{mg} / \mathrm{mL}),[1]=0.25 \mathrm{mM}(0.5$ $\mathrm{mg} / \mathrm{mL})$.

It is also worth to note that the spectrum of the hybrid gel (in a cuvette) is slightly blue-shifted as compared to the spectrum in pure dichloromethane (maximum at $682 \mathrm{~nm}$, see Figure 4). This is a strong indication that cluster $\mathbf{1}$ is not freely moving in the solvent pools created by the entangled fibres of $\mathbf{2}$, but stays in close contact with such structures, and the shift is a consequence of the different polarity of the environment where the cluster is entrapped. ESI-MS analysis of organogels containing 10\% of cluster, both in DCM and in toluene, did not afford any peak corresponding to acetate exchange by molecules of gelator. In consequence we hypothesize that the interaction between clusters and fibres is supramolecular, with TBA cations playing an intercalation role (van der Waals forces would be responsible of the association between butyl chains of TBA and nonyl chains of gelator). 

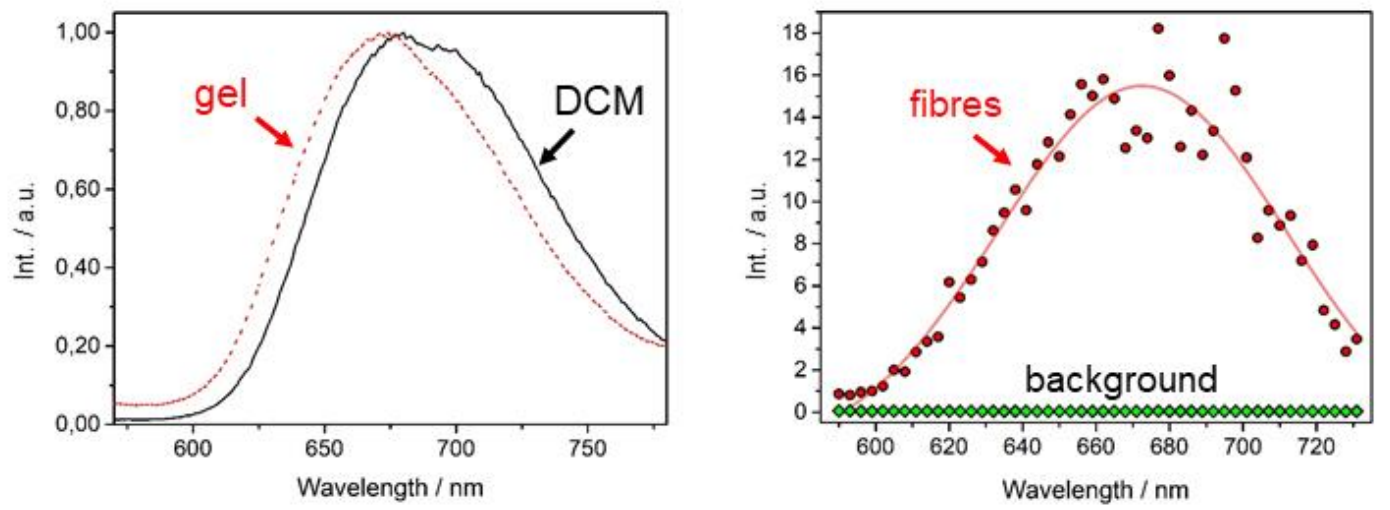

Figure 4 Left: phosphorescence emission measured in cuvette in a spectrofluorometer $\left(\lambda_{\mathrm{ex}}=400\right.$ $\mathrm{nm}$ ) of $\mathbf{1}$ in dichloromethane solution (black curve) and in gel formed by $\mathbf{2}$ (red dotted curve). Conditions: [2] $=14.6 \mathrm{mM}(5 \mathrm{mg} / \mathrm{mL}),[1]=0.03 \mathrm{mM}(0.06 \mathrm{mg} / \mathrm{mL})$. Right: phosphorescence emission of the red fibres measured in the confocal microscope along with the black background. Conditions: [2] $=14.6 \mathrm{mM}(5 \mathrm{mg} / \mathrm{mL}),[1]=0.25 \mathrm{mM}(0.5 \mathrm{mg} / \mathrm{mL})$.

Another feature that can be noticed in the spectrum of gel samples containing $\mathbf{1}$ is that it becomes sharper in comparison to 1 in DCM solution. As it can be seen in Figure 4 (left), the phosphorescence of $\mathbf{1}$ in solution is comprised by a broad band centered at $682 \mathrm{~nm}$ and a shoulder at ca. $700 \mathrm{~nm}$. It has been reported that this multiple emission arises from the existence of several excited triplet states. ${ }^{50,51}$ It can be concluded that stacking of $\mathbf{1}$ to the gel fibres induces a redistribution of the relative contribution of each triplet state to the total emission.

The chromatic coordinates (CIE1931 standard) of the doped gel were calculated, resulting in $\mathrm{x}=0.725$ and $\mathrm{y}=0.274$, which qualifies the hybrid as a deep-red dye (requisite $x \geq 0.670$ ). The xerogel material, formed after evaporation of the solvent (Figure S3, Supporting Information), displayed coordinates $\mathrm{x}=0.713$ and $\mathrm{y}=0,268$. Chromatic diagrams of both organogel and xerogel can be seen in the Figure S2 of the Supporting 
Information. Analogous $(\mathrm{x}, \mathrm{y})$ values have been reported for hexanuclear molybdenum complexes entrapped in organic polymers. ${ }^{25}$ The photoluminescence quantum yield (PLQY) of gel and xerogel samples resulted $2.2 \%$ and $6.1 \%$, respectively. Samples were measured in aerated conditions and hence those values reflect the quenching of the excited states by oxygen, leading to ${ }^{1} \mathrm{O}_{2}$. As a matter of fact, the most remarkable property of the organogels here reported is their ability to catalyze photo-oxygenations via the generation of ${ }^{1} \mathrm{O}_{2}$ upon illumination. In order to prove this property two benchmark oxidations were tested: the reaction of 9,10-dimethylanthracene (DMA) with ${ }^{1} \mathrm{O}_{2}$ to yield the corresponding endoperoxide and the transformation of 1,5-dihydroxynaphthalene (DHN) to juglone (see reactions in Figure 5). In both cases the reactions were followed easily by means of UVvis absorption spectroscopy, and the kinetic observed constants $\left(\mathrm{k}_{\mathrm{obs}}\right)$ were calculated after fitting to a pseudo-first order model, according to the literature. ${ }^{31}$

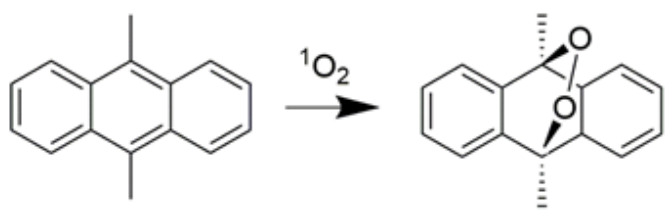

DMA

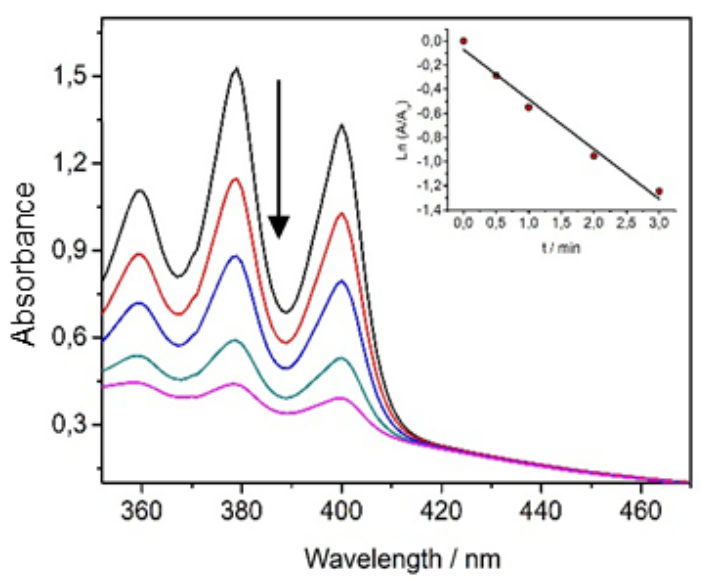

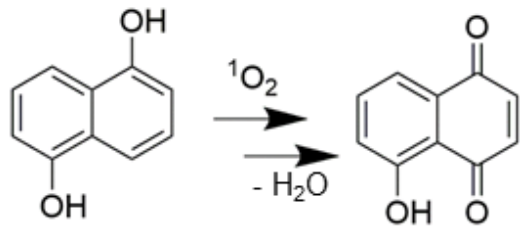

DHN

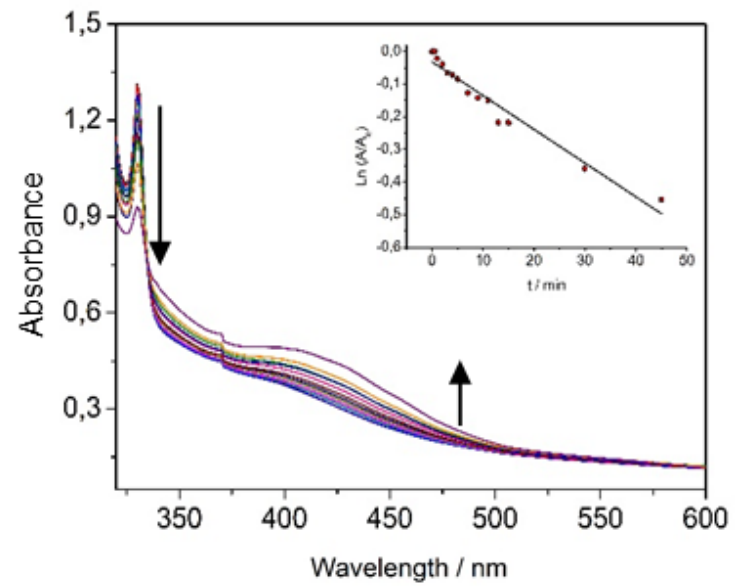


Figure 5. Illustrative UV-vis spectra monitoring the photo-oxygenation reactions of DMA (left) and DHN (right) photocatalyzed by 1 entrapped in a dichloromethane gel of $\mathbf{2}$. Conditions: [2] = $14.6 \mathrm{mM}(5 \mathrm{mg} / \mathrm{mL}),[1]=0.03 \mathrm{mM}(0.06 \mathrm{mg} / \mathrm{mL})$.

A gel of 2 entrapping 1 in dichloromethane induces the photooxygenation of DMA at a remarkable rate of $0.415 \mathrm{~min}^{-1}$. This value is not much lower than the value recorded in pure dichloromethane $\left(0.563 \mathrm{~min}^{-1}\right)$. It must be taken into account that the photoactivity of supported photosensitizers, as described in the literature, drop drastically when immobilised on materials. ${ }^{17}$ Gels prepared in toluene also showed activity for the photooxidation of DMA, although in this case the difference between $\mathrm{k}_{\mathrm{obs}}(\mathrm{gel})$ and $\mathrm{k}_{\mathrm{obs}}$ (solution) was higher (0.042 vs $0.139 \mathrm{~min}^{-1}$ respectively) than in DCM. The higher reactivity in DCM as compared to toluene must be due to the different singlet oxygen lifetime in those solvents (91 us in DCM, 29 us in toluene). ${ }^{52}$ The reactivity of DHN to produce juglone also was measured in a DCM gel entrapping $1\left(\mathrm{k}_{\mathrm{obs}}=0.010 \mathrm{~min}^{-1}\right)$ and for free 1 in DCM $\left(\mathrm{k}_{\mathrm{obs}}=0.018 \mathrm{~min}^{-1}\right)$. LED lamps used for this study emit very low infrared radiation, so no increase of temperature of the gels took place during the reactions. See illustrative examples of irradiations in Figure 5 and all the kinetic values in Table 1. It must be noted that the comparison between rate constants here reported must be done with care since light scattering in the organogels made very difficult to assure that all samples absorbed the same number of photons (despite the concentration of cluster was the same in all cases). However, the kinetics here reported can serve as a qualitative confirmation that photochemical activity is maintained in the hybrid gels. As a matter of fact, the outcome of preparing gels doped with clusters was not predictable, since negative events such as cluster aggregation or decomposition, or quenching of the excited state by the fibres, could have taken place, which was not the case. 
Table 1. Pseudo-first order kinetic constants for the oxygenation of DMA and DHN in gel and in solution.

\begin{tabular}{llll}
\hline Substrate & Sample & Solvent & kobs $\cdot \mathbf{1 0} \mathbf{( \mathbf { m i n } ^ { - 1 } )}$ \\
\hline DMA & $\mathbf{1}$ in gel & DCM & $415 \pm 33$ \\
DMA & $\mathbf{1}$ in solution & DCM & $563 \pm 36$ \\
DMA & Solution blank & DCM & $6.2 \pm 0.4$ \\
DMA & Gel blank & DCM & $17 \pm 2$ \\
DMA & $\mathbf{1}$ in gel & Toluene & $42.5 \pm 0.4$ \\
DMA & $\mathbf{1}$ in solution & Toluene & $139 \pm 2$ \\
DMA & Solution blank & Toluene & $0.6 \pm 0.8$ \\
DMA & Gel blank & Toluene & $1 \pm 3$ \\
DHN & $\mathbf{1}$ in gel & DCM & $10.3 \pm 0.6$ \\
DHN & $\mathbf{1}$ in solution & DCM & $18 \pm 1$ \\
DHN & Solution blank & DCM & $0.6 \pm 0.1$ \\
DHN & Gel blank & DCM & $4.2 \pm 0.5$ \\
\hline
\end{tabular}

Conditions: $[2]=14.6 \mathrm{mM}(5 \mathrm{mg} / \mathrm{mL}),[1]=0.03 \mathrm{mM}(0.06 \mathrm{mg} / \mathrm{mL},[\mathrm{DMA}]=[\mathrm{DHN}]=0.1$ $\mathrm{mM}$. Aerated dichloromethane or toluene were used as solvents. $\mathrm{T}=25^{\circ} \mathrm{C}$. Blanks show minor reactivity due to self-photosensitization.

In summary, a molecular organogel has been used for the first time as support for a photoactive hexanuclear molybdenum cluster cluster of formula $\mathrm{TBA}_{2}\left[\mathrm{Mo}_{6} \mathrm{I}_{8} \mathrm{Ac}_{6}\right](\mathrm{TBA}=$ tetrabutylammmonium, $\mathrm{Ac}=$ acetate). Electron and confocal microscopic analyses showed the alignment of the nanoclusters of $\mathbf{1}$ to the 1D self-assembled fibres formed by $\mathbf{2}$ and fluorescence spectroscopy corroborated the interaction of the emissive clusters with the fibres. The new hybrid system is a deep-red emissive material (phosphorescence maximum at ca. $680 \mathrm{~nm}$ ), with chromatic coordinates $\mathrm{x}=0.725, \mathrm{y}=0.274$, capable of generating efficiently ${ }^{1} \mathrm{O}_{2}$ upon illumination with white light. Photo-oxygenation reaction rates (substrates 9,10-dimethylanthracene and 1,5dihydroxynaphthalene) recorded in gel state, in dichloromethane, were of the same order of 
magnitude as those recorded in solution. The results here presented can be inscribed within the emerging field of intra-gel photochemistry. ${ }^{53-56}$ A practical advantage of the gel-photosensitizer systems here presented could be the potential induction of regio- and stereoselectivity if oxygenations take place close to the fiber. In this case, the fibrillary network would be acting as a templating agent. It must be recalled that self-assembled fibrillary networks made with amino acid derivatives, present chirality, so it is expected that association of the appropriate substrate to the photosensitizing chiral fiber would give rise to a preferential oxygenation mode. Few examples of selective photoxygenations have been presented in the literature, for instance, using amino acids,

zeolites or metallic complexes. ${ }^{57-60}$ Current work is in progress along this direction using substrates prone to association with the self-assembled gelator.

\section{ASSOCIATED CONTENT}

\section{Supporting Information}

Experimental section, melting curves, xerogel pictures, EDS analyses and additional TEM / STEM pictures.

\section{AUTHOR INFORMATION}

\section{Corresponding Author}

*E-mail: francisco.galindo@uji.es

*E-mail: miravet@uji.es 


\section{ORCID}

Felip-León, Carles: 0000-0002-2476-3243

Angulo-Pachón, César A.: 0000-0002-3225-3091

Sokolov, Maksim N.: 0000-0001-9361-4594

Miravet, Juan F.: 0000-0003-0946-3784

Galindo, Francisco: 0000-0003-0826-6084

\section{CONFLICTS OF INTEREST}

There are no conflicts to declare.

\section{ACKNOWLEDGEMENTS}

This study was supported by Ministerio de Economía y Competitividad of Spain (grant CTQ2015-71004-R) and Universitat Jaume I (grant P1.1B2015-76). Technical assistance from SCIC/Universitat Jaume I (M. C. Peiró) is acknowledged. Also M. Vallés (UJI) is acknowledged for PLQY measurements.

\section{REFERENCES}

(1) Maverick, A. W.; Najdzionek, J. S.; Mackenzie, D.; Nocera, D. G.; Gray, H. B. Spectroscopic , Electrochemical, and Photochemical Properties of Molybdenum ( 11 ) and Tungsten ( 11 ) Halide Clusters. J. Am. Chem. Soc. 1983, 105 (7), 1878-1882.

(2) Jackson, J. A.; Newsham, M. D.; Worsham, C.; Nocera, D. G. Efficient Singlet Oxygen Generation from Polymers Derivatized with Hexanuclear Molybdenum Clusters. Chem. Mater. 1996, 8 (2), 558-564. https://doi.org/10.1021/cm950443f.

(3) Mikhailov, M. A.; Brylev, K. A.; Abramov, P. A.; Sakuda, E.; Akagi, S.; Ito, A.; Kitamura, 
N.; Sokolov, M. N. Synthetic Tuning of Redox, Spectroscopic, and Photophysical Properties of $\{$ Mo6I8 $\} 4+$ Core Cluster Complexes by Terminal Carboxylate Ligands. Inorg. Chem. 2016, 55 (17), 8437-8445. https://doi.org/10.1021/acs.inorgchem.6b01042.

(4) Evtushok, D. V.; Melnikov, A. R.; Vorotnikova, N. A.; Vorotnikov, Y. A.; Ryadun, A. A.; Kuratieva, N. V.; Kozyr, K. V.; Obedinskaya, N. R.; Kretov, E. I.; Novozhilov, I. N.; Mironov, Y. V.; Stass, D. V.; Efremova, O. A.; Shestopalov, M. A. A Comparative Study of Optical Properties and X-Ray Induced Luminescence of Octahedral Molybdenum and Tungsten Cluster Complexes. Dalt. Trans. 2017, 46 (35), 11738-11747. https://doi.org/10.1039/c7dt01919j.

(5) Mikhaylov, M. A.; Abramov, P. A.; Komarov, V. Y.; Sokolov, M. N. Cluster Aqua/Hydroxocomplexes Supporting Extended Hydrogen Bonding Networks. Preparation and Structure of a Unique Series of Cluster Hydrates $\left[\mathrm{Mo}_{6} \mathrm{I}_{8}(\mathrm{OH})_{4}\left(\mathrm{H}_{2} \mathrm{O}\right)_{2}\right] \cdot \mathrm{nH}_{2} \mathrm{O}(\mathrm{n}=2,12$, 14). Polyhedron 2017, 122, 241-246. https://doi.org/10.1016/j.poly.2016.11.011.

(6) Volostnykh, M. V.; Mikhaylov, M. A.; Sinelshchikova, A. A.; Kirakosyan, G. A.; Martynov, A. G.; Grigoriev, M. S.; Piryazev, D. A.; Tsivadze, A. Y.; Sokolov, M. N.; Gorbunova, Y. G. Hybrid Organic-inorganic Supramolecular Systems Based on a Pyridine End-Decorated Molybdenum(II) Halide Cluster and Zinc(II) Porphyrinate. Dalt. Trans. 2019, 1835-1842. https://doi.org/10.1039/C8DT04452J.

(7) Kirakci, K.; Zelenka, J.; Rumlová, M.; Cvačka, J.; Ruml, T.; Lang, K. Cationic Octahedral Molybdenum Cluster Complexes Functionalized with Mitochondria-Targeting Ligands: Photodynamic Anticancer and Antibacterial Activities. Biomater. Sci. 2019, 7, 1386-1392 https://doi.org/10.1039/C8BM01564C. 
(8) Grasset, F.; Molard, Y.; Cordier, S.; Dorson, F.; Mortier, M.; Perrin, C.; Guilloux-Viry, M.;

Sasaki, T.; Haneda, H. When "Metal Atom Clusters" Meet ZnO Nanocrystals: A ((n$\left.\left.\mathrm{C}_{4} \mathrm{H}_{9}\right)_{4} \mathrm{~N}\right)_{2} \mathrm{Mo}_{6} \mathrm{Br}_{14} @ \mathrm{ZnO} \quad$ Hybrid. Adv. Mater. 2008, $20 \quad$ (9), 1710-1715. https://doi.org/10.1002/adma.200701845.

(9) Molard, Y.; Dorson, F.; Cîrcu, V.; Roisnel, T.; Artzner, F.; Cordier, S. Clustomesogens: Liquid Crystal Materials Containing Transition-Metal Clusters. Angew. Chemie - Int. Ed. 2010, 49 (19), 3351-3355. https://doi.org/10.1002/anie.201000325.

(10) Korshin, D. E.; Ziganshina, A. Y.; Mukhitova, R. K.; Kharlamov, S. V; Latypov, S. K.; Sokolov, M. N.; Fedin, V. P.; Konovalov, A. I. PH-Controlled Photoinduced Electron Transfer in the $\left[\left(\mathrm{Mo}_{6} \mathrm{Cl}_{8}\right) \mathrm{L}_{6}\right]$ - System. Org. Lett. 2011, 13 (3), 6-9.

(11) Sokolov, M. N.; Mihailov, M. A.; Peresypkina, E. V.; Brylev, K. A.; Kitamura, N.; Fedin, V. P. Highly Luminescent Complexes $\left[\mathrm{Mo}_{6} \mathrm{X}_{8}\left(\mathrm{n}-\mathrm{C}_{3} \mathrm{~F}_{7} \mathrm{COO}\right)_{6}\right]^{2-}(\mathrm{X}=\mathrm{Br}$, I). Dalt. Trans. 2011, 40 (24), 6375-6377. https://doi.org/10.1039/c1dt10376h.

(12) Kirakci, K.; Kubát, P.; Dušek, M.; Fejfarová, K.; Š́cha, V.; Mosinger, J.; Lang, K. A Highly Luminescent Hexanuclear Molybdenum Cluster - A Promising Candidate toward Photoactive Materials. Eur. J. Inorg. Chem. 2012, 8 (19), 3107-3111. https://doi.org/10.1002/ejic.201200402.

(13) Sokolov, M. N.; Mikhailov, M. A.; Brylev, K. A.; Virovets, A. V.; Vicent, C.; Kompankov, N. B.; Kitamura, N.; Fedin, V. P. Alkynyl Complexes of High-Valence Clusters. Synthesis and Luminescence Properties of $\left[\mathrm{Mo}_{6} \mathrm{I}_{8}(\mathrm{C} \equiv \mathrm{CC}(\mathrm{O}) \mathrm{OMe})_{6}\right]^{2-}$, the First Complex with Exclusively Organometallic Outer Ligands in the Family of Octahedral $\left\{\mathrm{M}_{6} \mathrm{X}_{8}\right\}$ Clusters. Inorg. Chem. 2013, 52 (21), 12477-12481. https://doi.org/10.1021/ic401377g. 
(14) Efremova, O. A.; Vorotnikov, Y. A.; Brylev, K. A.; Vorotnikova, N. A.; Novozhilov, I. N.; Kuratieva, N. V.; Edeleva, M. V.; Benoit, D. M.; Kitamura, N.; Mironov, Y. V.; Shestopalov, M. A.; Sutherland, A. J. Octahedral Molybdenum Cluster Complexes with Aromatic Sulfonate Ligands. Dalt. Trans. 2016, 45 (39), 15427-15435. https://doi.org/10.1039/c6dt02863b.

(15) Mikhailov, M. A.; Brylev, K. A.; Virovets, A. V.; Gallyamov, M. R.; Novozhilov, I.; Sokolov, M. N. Complexes of $\left\{\mathrm{Mo}_{6} \mathrm{I}_{8}\right\}$ with Nitrophenolates: Synthesis and Luminescence. New J. Chem. 2016, 40 (2), 1162-1168. https://doi.org/10.1039/c5nj02246k.

(16) Fabregat, V.; Burguete, M. I.; Luis, S. V.; Galindo, F. Improving Photocatalytic Oxygenation Mediated by Polymer Supported Photosensitizers Using Semiconductor Quantum Dots as "Light Antennas." $R S C$ Adv. 2017, 7, 35154-35158. https://doi.org/10.1039/c7ra06036j.

(17) Burguete, M. I.; Galindo, F.; Gavara, R.; Luis, S. V.; Moreno, M.; Thomas, P.; Russell, D. A. Singlet Oxygen Generation Using a Porous Monolithic Polymer Supported Photosensitizer: Potential Application to the Photodynamic Destruction of Melanoma Cells. Photochem. Photobiol. Sci. 2009, 8, 37-44. https://doi.org/10.1039/b810921d.

(18) Robinson, L. M.; Shriver, D. F. Synthesis and photophysical properties of polymer-bound hexanuclear molybdenum clusters. J. Coord. Chem. 1996, 37, 119-129.

(19) Ghosh, R. N.; Baker, G. L.; Ruud, C.; Nocera, D. G. Fiber-Optic Oxygen Sensor Using Molybdenum Chloride Cluster Luminescence. Appl. Phys. Lett. 1999, 75 (19), 2885-2887. https://doi.org/10.1063/1.125180. 
(20) Amela-Cortes, M.; Paofai, S.; Cordier, S.; Folliot, H.; Molard, Y. Tuned Red NIR Phosphorescence of Polyurethane Hybrid Composites Embedding Metallic Nanoclusters for Oxygen Sensing. Chem. Commun. 2015, 51 (38), 8177-8180. https://doi.org/10.1039/c5cc01867f.

(21) Fabre, B.; Molard, Y.; Perrin, C.; Ababou-girard, S.; Godet, C. Electrochemical and Charge Transport Behavior of Molybdenum-Based Metallic Cluster Layers Immobilized on Modified n - and p -Type Si ( 111 ) Surfaces. J. Phys. Chem. C 2009, 111, 17437-17446.

(22) Cordier, S.; Fabre, B. Assembly of Hexamolybdenum Metallic Clusters on Silicon Surfaces. ChemPhysChem 2007, 8, 2086-2090. https://doi.org/10.1002/cphc.200700499.

(23) Godet, C.; Ababou-Girard, S.; Fabre, B.; Molard, Y.; Fadjie-Djomkam, A. B.; Députier, S.; Guilloux-Viry, M.; Cordier, S. Surface Immobilization of Mo6I8octahedral Cluster Cores on Functionalized Amorphous Carbon Using a Pyridine Complexation Strategy. Diam. Relat. Mater. 2015, 55, 131-138. https://doi.org/10.1016/j.diamond.2015.03.011.

(24) Molard, Y.; Labbé, C.; Cardin, J.; Cordier, S. Sensitization of Er3+ infrared Photoluminescence Embedded in a Hybrid Organic-Inorganic Copolymer Containing Octahedral Molybdenum Clusters. Adv. Funct. Mater. 2013, 23 (38), 4821-4825. https://doi.org/10.1002/adfm.201300417.

(25) Amela-Cortes, M.; Garreau, A.; Cordier, S.; Faulques, E.; Duvail, J. L.; Molard, Y. Deep Red Luminescent Hybrid Copolymer Materials with High Transition Metal Cluster Content. J. Mater. Chem. C 2014, 2 (8), 1545-1552. https://doi.org/10.1039/c3tc31309c.

(26) Amela-Cortes, M.; Molard, Y.; Paofai, S.; Desert, A.; Duvail, J. L.; Naumov, N. G.; Cordier, 
S. Versatility of the Ionic Assembling Method to Design Highly Luminescent PMMA Nanocomposites Containing $\left[\mathrm{M}_{6} \mathrm{Q}_{8}^{\mathrm{i}} \mathrm{L}_{6}^{\mathrm{a}}\right]^{\mathrm{n}-}$ Octahedral Nano-Building Blocks. Dalt. Trans. 2016, 45 (1), 237-245. https://doi.org/10.1039/c5dt03734d.

(27) Efremova, O. A.; Brylev, K. A.; Vorotnikov, Y. A.; Vejsadová, L.; Shestopalov, M. A.; Chimonides, G. F.; Mikes, P.; Topham, P. D.; Kim, S. J.; Kitamura, N.; Sutherland, A. J. Photoluminescent Materials Based on PMMA and a Highly-Emissive Octahedral Molybdenum Metal Cluster Complex. J. Mater. Chem. C 2016, 4 (3), 497-503. https://doi.org/10.1039/c5tc03204k.

(28) Brandhonneur, N.; Hatahet, T.; Amela-Cortes, M.; Molard, Y.; Cordier, S.; Dollo, G. Molybdenum Cluster Loaded PLGA Nanoparticles: An Innovative Theranostic Approach for the Treatment of Ovarian Cancer. Eur. J. Pharm. Biopharm. 2018, 125 (January), 95105. https://doi.org/10.1016/j.ejpb.2018.01.007.

(29) Kirakci, K.; Š́cha, V.; Holub, J.; Kubát, P.; Lang, K. Luminescent Hydrogel Particles Prepared by Self-Assembly of $\beta$-Cyclodextrin Polymer and Octahedral Molybdenum Cluster Complexes. Inorg. Chem. 2014, 53 (24), 13012-13018. https://doi.org/10.1021/ic502144z.

(30) Efremova, O. A.; Shestopalov, M. A.; Chirtsova, N. A.; Smolentsev, A. I.; Mironov, Y. V.; Kitamura, N.; Brylev, K. A.; Sutherland, A. J. A Highly Emissive Inorganic Hexamolybdenum Cluster Complex as a Handy Precursor for the Preparation of New Luminescent Materials. Dalt. Trans. 2014, 43 (16), 6021-6025. https://doi.org/10.1039/c3dt53126k.

(31) Beltrán, A.; Mikhailov, M.; Sokolov, M. N.; Pérez-Laguna, V.; Rezusta, A.; Revillo, M. J.; 
Galindo, F. A Photobleaching Resistant Polymer Supported Hexanuclear Molybdenum Iodide Cluster for Photocatalytic Oxygenations and Photodynamic Inactivation of: Staphylococcus Aureus. J. Mater. Chem. B 2016, 4, 5975-5979. https://doi.org/10.1039/c6tb01966h.

(32) Kirakci, K.; Kubát, P.; Fejfarová, K.; Martinčík, J.; Nikl, M.; Lang, K. X-Ray Inducible Luminescence and Singlet Oxygen Sensitization by an Octahedral Molybdenum Cluster Compound: A New Class of Nanoscintillators. Inorg. Chem. 2016, 55 (2), 803-809. https://doi.org/10.1021/acs.inorgchem.5b02282.

(33) Vorotnikova, N. A.; Efremova, O. A.; Tsygankova, A. R.; Brylev, K. A.; Edeleva, M. V.; Kurskaya, O. G.; Sutherland, A. J.; Shestopalov, A. M.; Mironov, Y. V.; Shestopalov, M. A. Characterization and Cytotoxicity Studies of Thiol-Modified Polystyrene Microbeads Doped with $\left[\left\{\mathrm{Mo}_{6} \mathrm{X}_{8}\right\}\left(\mathrm{NO}_{3}\right)_{6}\right]^{2-}(\mathrm{X}=\mathrm{Cl}, \mathrm{Br}$, I). Polym. Adv. Technol. 2016, 27 (7), 922928. https://doi.org/10.1002/pat.3749.

(34) Felip-León, C.; Arnau Del Valle, C.; Pérez-Laguna, V.; Isabel Millán-Lou, M.; Miravet, J. F.; Mikhailov, M.; Sokolov, M. N.; Rezusta-López, A.; Galindo, F. Superior Performance of Macroporous over Gel Type Polystyrene as a Support for the Development of PhotoBactericidal Materials. J. Mater. Chem. B 2017, 5, 6058-6064. https://doi.org/10.1039/c7tb01478c.

(35) Vorotnikova, N. A.; Edeleva, M. V.; Kurskaya, O. G.; Brylev, K. A.; Shestopalov, A. M.; Mironov, Y. V.; Sutherland, A. J.; Efremova, O. A.; Shestopalov, M. A. One-Pot Synthesis of $\{$ Mo618\}4+-Doped Polystyrene Microspheres via a Free Radical Dispersion Copolymerisation Reaction. Polym. Int. 2017, 66 (12), 1906-1912. 
https://doi.org/10.1002/pi.5473.

(36) Aubert, T.; Cabello-Hurtado, F.; Esnault, M. A.; Neaime, C.; Lebret-Chauvel, D.; Jeanne, S.; Pellen, P.; Roiland, C.; Le Polles, L.; Saito, N.; Kimono, K.; Haneda, H.; Ohashi, N.;

Grasset, F.; Cordier, S. Extended Investigations on Luminescent $\mathrm{Cs}_{2}\left[\mathrm{Mo}_{6} \mathrm{Br}_{14}\right] @ \mathrm{SiO}_{2}$ nanoparticles: Physico-Structural Characterizations and Toxicity Studies. J. Phys. Chem. C 2013, 117 (39), 20154-20163. https://doi.org/10.1021/jp405836q.

(37) Vorotnikov, Y. A.; Efremova, O. A.; Vorotnikova, N. A.; Brylev, K. A.; Edeleva, M. V.; Tsygankova, A. R.; Smolentsev, A. I.; Kitamura, N.; Mironov, Y. V.; Shestopalov, M. A. On the Synthesis and Characterisation of Luminescent Hybrid Particles: Mo6 metal Cluster Complex/SiO $2 . R S C A d v$. 2016, 6 (49), 43367-43375. https://doi.org/10.1039/c6ra04321f.

(38) Solovieva, A. O.; Vorotnikov, Y. A.; Trifonova, K. E.; Efremova, O. A.; Krasilnikova, A. A.; Brylev, K. A.; Vorontsova, E. V.; Avrorov, P. A.; Shestopalova, L. V.; Poveshchenko, A. F.; Mironov, Y. V.; Shestopalov, M. A. Cellular Internalisation, Bioimaging and Dark and Photodynamic Cytotoxicity of Silica Nanoparticles Doped by $\left\{\mathrm{Mo}_{6} \mathrm{I}_{8}\right\}^{4+}$ metal Clusters. J. Mater. Chem. B 2016, 4 (28), 4839-4846. https://doi.org/10.1039/c6tb00723f.

(39) Neaime, C.; Amela-Cortes, M.; Grasset, F.; Molard, Y.; Cordier, S.; Dierre, B.; Mortier, M.; Takei, T.; Takahashi, K.; Haneda, H.; Verelst, M.; Lechevallier, S. Time-Gated Luminescence Bioimaging with New Luminescent Nanocolloids Based on [Mo6 $\left.\mathrm{I}_{8}\left(\mathrm{C}_{2} \mathrm{~F}_{5} \mathrm{COO}\right)_{6}\right]^{2-}$ Metal Atom Clusters. Phys. Chem. Chem. Phys. 2016, 18 (43), 3016630173. https://doi.org/10.1039/C6CP05290H.

(40) Elistratova, J.; Mukhametshina, A.; Kholin, K.; Nizameev, I.; Mikhailov, M.; Sokolov, M.; Khairullin, R.; Miftakhova, R.; Shammas, G.; Kadirov, M.; Petrov, K.; Rizvanov, A.; 
Mustafina, A. Interfacial Uploading of Luminescent Hexamolybdenum Cluster Units onto Amino-Decorated Silica Nanoparticles as New Design of Nanomaterial for Cellular Imaging and Photodynamic Therapy. J. Colloid Interface Sci. 2019, 538, 387-396. https://doi.org/10.1016/j.jcis.2018.12.013.

(41) Aubert, T.; Nerambourg, N.; Saito, N.; Haneda, H.; Ohashi, N.; Mortier, M.; Cordier, S.; Grasset, F. Tunable Visible Emission of Luminescent Hybrid Nanoparticles Incorporating Two Complementary Luminophores: $\mathrm{ZnO}$ Nanocrystals and $\left[\mathrm{Mo}_{6} \mathrm{Br}_{14}\right]^{2-}$ Nanosized Cluster Units. Part. Part. Syst. Charact. 2013, 30 (1), 90-95. https://doi.org/10.1002/ppsc.201200047.

(42) Svezhentseva, E. V.; Solovieva, A. O.; Vorotnikov, Y. A.; Kurskaya, O. G.; Brylev, K. A.; Tsygankova, A. R.; Edeleva, M. V.; Gyrylova, S. N.; Kitamura, N.; Efremova, O. A.; Shestopalov, M. A.; Mironov, Y. V.; Shestopalov, A. M. Water-Soluble Hybrid Materials Based on $\left\{\mathrm{Mo}_{6} \mathrm{X}_{8}\right\}^{4+}(\mathrm{X}=\mathrm{Cl}, \mathrm{Br}, \mathrm{I})$ Cluster Complexes and Sodium Polystyrene Sulfonate. New J. Chem. 2017, 41 (4), 1670-1676. https://doi.org/10.1039/c6nj03469a.

(43) Segarra-Maset, M. D.; Nebot, V. J.; Miravet, J. F.; Escuder, B. Control of Molecular Gelation by Chemical Stimuli. Chem. Soc. Rev. 2013, 42 (17), 7086-7098. https://doi.org/10.1039/c2cs35436e.

(44) Draper, E. R.; Adams, D. J. Low-Molecular-Weight Gels: The State of the Art. Chem 2017, 3 (3), 390-410. https://doi.org/10.1016/j.chempr.2017.07.012.

(45) Steed, J. W. Supramolecular Gel Chemistry: Developments over the Last Decade. Chem. Commun. 2011, 47 (5), 1379-1383. https://doi.org/10.1039/c0cc03293j. 
(46) Burguete, M. I.; Izquierdo, M. A.; Galindo, F.; Luis, S. V. Time Resolved Fluorescence of Naproxen in Organogel Medium. Chem. Phys. Lett. 2008, 460 (4-6), 503-506. https://doi.org/10.1016/j.cplett.2008.06.045.

(47) Wadhavane, P. D.; Galian, R. E.; Izquierdo, M. A.; Aguilera-Sigalat, J.; Galindo, F.; Schmidt, L.; Burguete, M. I.; Pérez-Prieto, J.; Luis, S. V. Photoluminescence Enhancement of CdSe Quantum Dots: A Case of Organogel-Nanoparticle Symbiosis. J. Am. Chem. Soc. 2012, 134, 20554-20563. https://doi.org/10.1021/ja310508r.

(48) Wadhavane, P. D.; Izquierdo, M. A.; Galindo, F.; Burguete, M. I.; Luis, S. V. OrganogelQuantum Dots Hybrid Materials Displaying Fluorescence Sensitivity and Structural Stability towards Nitric Oxide. Soft Matter 2012, 8, 4373-4381. https://doi.org/10.1039/c2sm07175d.

(49) Felip-León, C.; Díaz-Oltra, S.; Galindo, F.; Miravet, J. F. Chameleonic, Light Harvesting Photonic Gels Based on Orthogonal Molecular Fibrillization. Chem. Mater. 2016, 28, 7964-7972. https://doi.org/10.1021/acs.chemmater.6b03137.

(50) Costuas, K.; Garreau, A.; Bulou, A.; Fontaine, B.; Cuny, J.; Gautier, R.; Mortier, M.; Molard, Y.; Duvail, J. L.; Faulques, E.; Cordier, S. Combined Theoretical and TimeResolved Photoluminescence Investigations of $\left[\mathrm{Mo}_{6} \mathrm{Br}_{8}{ }_{8} \mathrm{Br}_{6}^{\mathrm{a}}\right]^{2-}$ Metal Cluster Units: Evidence of Dual Emission. Phys. Chem. Chem. Phys. 2015, 17 (43), 28574-28585. https://doi.org/10.1039/c5cp03960f.

(51) Akagi, S.; Sakuda, E.; Ito, A.; Kitamura, N. Zero-Magnetic-Field Splitting in the Excited Triplet States of Octahedral Hexanuclear Molybdenum(II) Clusters: $\left[\left\{\mathrm{Mo}_{6} \mathrm{X}_{8}\right\}\left(n-\mathrm{C}_{3} \mathrm{~F}_{7}\right.\right.$ $\left.\mathrm{COO})_{6}\right]^{2-}(\mathrm{X}=\mathrm{Cl}, \mathrm{Br}$, or I). J. Phys. Chem. A 2017, 121 (38), 7148-7156. 
https://doi.org/10.1021/acs.jpca.7b06783.

(52) Salokhiddinov, K.I.; Byteva, I.M.; Gurinovich, G. P. Lifetime of Singlet Oxygen in Various Solvents. J. Appl. Spectrosc. 1981, 34 (7), 561-562.

(53) Galindo, F.; Burguete, M. I.; Gavara, R.; Luis, S. Fluorescence Quenching in Organogel as a Reaction Medium. J. Photochem. Photobiol. A: Chem. 2006, 178 (1), 57-61. https://doi.org/10.1016/j.jphotochem.2005.06.021.

(54) Dawn, A.; Fujita, N.; Haraguchi, S.; Sada, K.; Shinkai, S. An Organogel System Can Control the Stereochemical Course of Anthracene Photodimerization. Chem. Commun. 2009, 7345 (16), 2100-2102. https://doi.org/10.1039/b820565e.

(55) Pérez-Ruiz, R.; Díaz Díaz, D. Photophysical and Photochemical Processes in 3D SelfAssembled Gels as Confined Microenvironments. Soft Matter 2015, 11 (26), 5180-5187. https://doi.org/10.1039/c5sm00877h.

(56) Das, S.; Okamura, N.; Yagi, S.; Ajayaghosh, A. Supramolecular Gel Phase Controlled [4 + 2] Diels-Alder Photocycloaddition for Electroplex Mediated White Electroluminescence. $J$. Am. Chem. Soc. 2019, 141 (14), 5635-5639. https://doi.org/10.1021/jacs.9b00955.

(57) Li, X.; Ramamurthy, V. Selective Oxidation of Olefins within Organic Dye CationExchanged Zeolites. J. Am. Chem. Soc. 1996, 118 (43), 10666-10667. https://doi.org/10.1021/ja9623727.

(58) Lacombe, S.; Pigot, T. Materials for Selective Photo-Oxygenation vs. Photocatalysis: Preparation, Properties and Applications in Environmental and Health Fields. Catal. Sci. Technol. 2016, 6 (6), 1571-1592. https://doi.org/10.1039/c5cy01929j. 
(59) Córdova, A.; Sundén, H.; Engqvist, M.; Ibrahem, I.; Casas, J. The Direct Amino AcidCatalyzed Asymmetric Incorporation of Molecular Oxygen to Organic Compounds, J. Am. Chem. Soc. 2004, 126 (29) 8914-8915. https://doi.org/10.1021/ja047930t .

(60) Ding, W.; Lu, L. Q.; Zhou, Q. Q.; Wei, Y.; Chen, J. R.; Xiao, W. J. Bifunctional Photocatalysts for Enantioselective Aerobic Oxidation of $\beta$-Ketoesters. J. Am. Chem. Soc. 2017, 139 (1), 63-66. https://doi.org/10.1021/jacs.6b11418. 
For Table of Contents Only

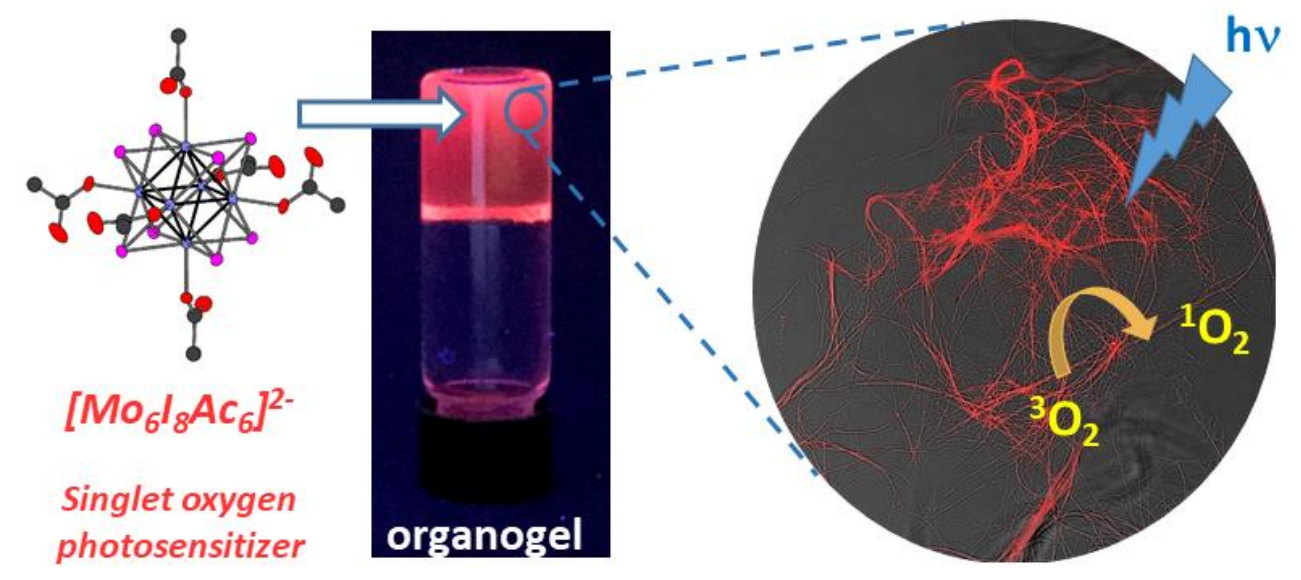

